\title{
Геоэкологическая оценка современного состояния разновозрастных хвостохранилищ рудника Карнасурт
}

Горячев А.А. ${ }^{1,2}$, Лащук В.В. ${ }^{3}$, Красавцева Е.А. ${ }^{1,2}$, Алфертьев Н.Л. ${ }^{4}$, Макаров Д.В. ${ }^{2}$

${ }^{1}$ ЛПТиТБА ФИЦ КНЦ РАН, Anamumbl,a.goryachev@ksc.ru; e.krasavtseva@ksc.ru

${ }^{2}$ ИППЭС ФИЦ КНЦ РАН, Anamumbl,mdv2008@mail.ru

${ }^{3}$ ИХТРЭМС ФИЦ КНЦ РАН, Anamumbl,v.lashchuk@ksc.ru

${ }^{4}$ АФ МГТУ, koba9527@gmail.com

Аннотация. Исследованы инженерно-геологические характеристики и минеральный состав I поля хвостохранилища Ловозерского ГОКа. Проведено сравнение этих показателей с намываемым в настоящее время полем. Рассмотрена зависимость интенсивности миграции фтора в раствор от времени взаимодействия и pH раствора при водном выщелачивании. Установлены основные показатели минерального состава и структуры, которые влияют на инженерно-геологическое, геохимическое и радиационное состояние мелкозернистого и пылеватого грунта.

Ключевые слова: Хвостохранилища, отходы обогащения, редкометальные руды, инженерногеологическая оценка, миграция фтора.

\section{Current state geoecological assessment of the different ages enrichment tailing dumps of the Karnasurt mine}

\author{
Goryachev A.A. ${ }^{1,2}$, Lashchuk V.V. ${ }^{3}$, Krasavtseva E.A. ${ }^{1,2}$, Alfertev N.L. ${ }^{4}$, Makarov D.V. ${ }^{2}$ \\ ${ }^{1}$ NTTSA FRC KSC RAS, Apatity, a.goryachev@ksc.ru; e.krasavtseva@ksc.ru \\ 2INEPFRC KSC RAS, Apatity,mdv2008@mail.ru \\ ${ }^{3}$ ICT FRC KSC RAS, Apatity,v.lashchuk@ksc.ru \\ ${ }^{4}$ MSTU, Apatity, koba9527@gmail.com
}

\begin{abstract}
The engineering-geological characteristics and mineral composition of the first field of the tailings of the Lovozersky GOK are investigated. A comparison of these indicators with the currently washed field. The dependence of the intensity of fluorine migration into the solution on the interaction time and the $\mathrm{pH}$ of the solution during aqueous leaching is considered. The main indicators of the mineral composition and structure that affect the engineering-geological, geochemical, and radiation state of fine-grained dusty soil are established.
\end{abstract}

Key words: Tailing dumps, enrichment wastes, rare metals ores, engineering-geological assessment, fluorine migration.

\section{Введение}

Ловозерский горно-обогатительный комбинат приурочен к месторождению редкоземельных элементов, относящихся преимущественно к массивам щелочных и ультращелочных горных пород (Пожиленко и др., 2002). На предприятии производится добыча и обогащение сырья на руднике Карнасурт. Основной продукцией предприятия являются лопаритовый и эвдиалитовый концентраты. За все время функционирования комбината образовалось два поля отходов обогащения. Первое поле эксплуатировалось с 1951 г. в течение чуть более трех десятилетий. В декабре 1985 г. предприятия ввело в эксплуатацию второе поле, куда в настоящее время осуществляется сброс пульпы и забор воды для повторного использования. Хранилища хвостов обогащения руд редких металлов разрушаются вследствие ветрового воздействия, химического выветривания, что приводит к переносу пылеватых частиц и миграции загрязняющих веществ с водными потоками. Таким образом, они представляют собой источник загрязнения окружающей природной среды, а следовательно, могут влиять на здоровье населения региона. Ежегодное приращение отходов составляет в настоящее время 450 тыс. тонн, в связи с чем необходим поиск методов снижения негативного воздействия хвостохранилища на окружающую природную среду. Дополнительное внимание к хвостам необходимо уделить вследствие того, что перерабатываемое предприятием сырье имеет повышенный ради- 


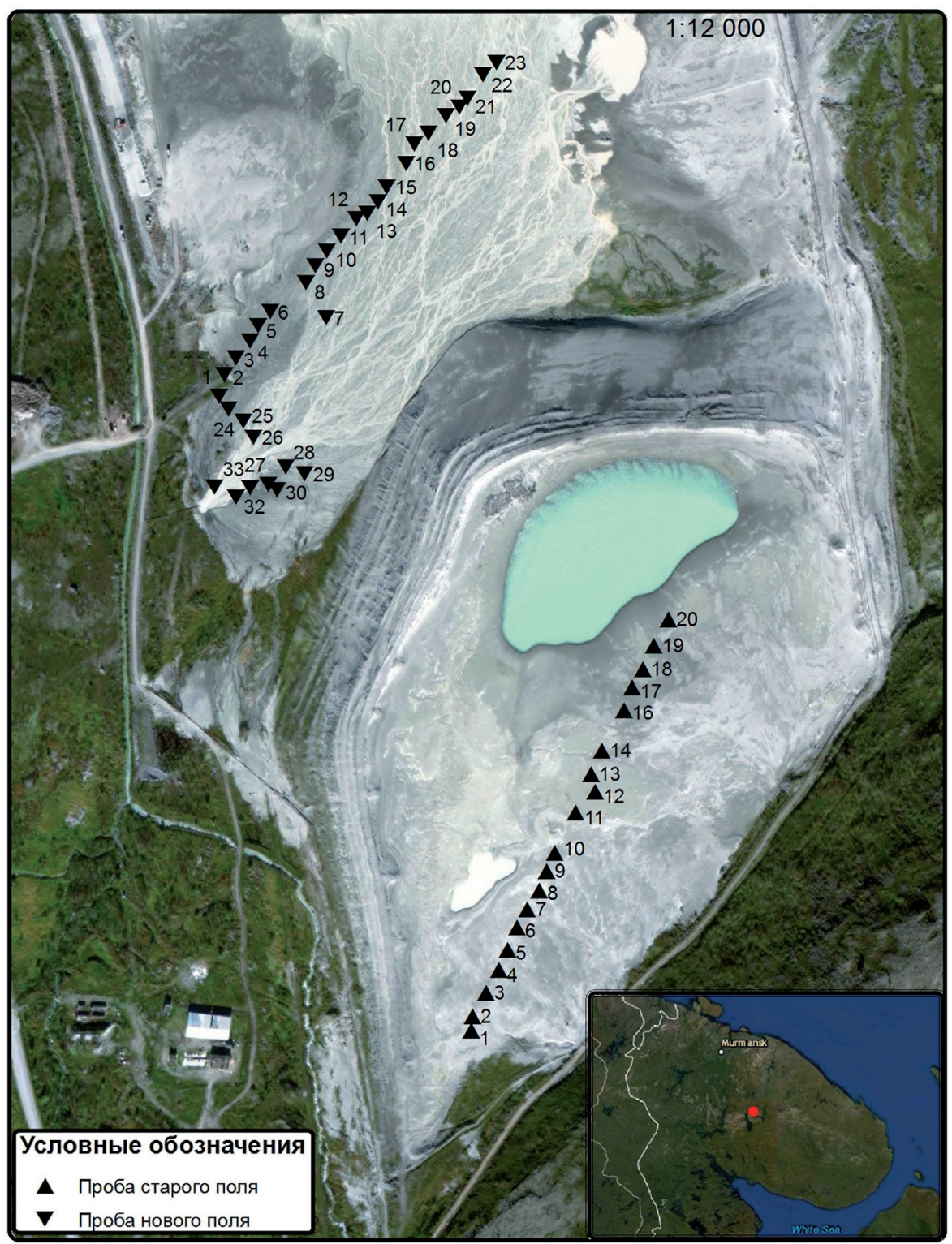

Рис. 1. Точки отбора проб на I (старое) и II (новое) полях отходов обогащения.

Fig. 1. Sampling points on the I (old) and II (new) enrichment tailing dumps.

ационный фон. Проведенные ранее исследования позволили установить торий-радиевый характер радиоактивности (Горячев и др., 2019 а).

Кроме того, вследствие большого объема накопленных отходов (6.7 млн. т), оба поля можно рассматривать как техногенное месторождение (Лащук, Горячев, 2019). Перспективным направлением переработки отходов является получение лопаритового концентрата флотацией, что, в свою очередь, позволит снизить удельную активность хвостов до требуемых показателей полевошпатового и нефелинового концентратов.

\section{Методика исследований}

Отбор проб поверхностного слоя хвостохранилищ осуществлялся методом режущего кольца вдоль поверхности пляжа (рис. 1). Этот метод применяется для связных и сыпучих грунтов, легко поддающихся вырезке. Выбор данного метода обусловлен тем, что только в жесткой таре могут быть сохранены объем и форма отобранных образцов таких грунтов.

Инженерно-геологические характеристики грунтов определяли в соответствии с ГОСТ 5180-84 «Грунты. Методы лабораторного определения физических характеристик». Данный стандарт рас- 
пространяется на грунты без жестких структурных связей и устанавливает методы лабораторного определения их физических характеристик - влажности и плотности при исследованиях грунтов для строительства. В лабораторных условиях определен гранулометрический состав хвостов обогащения обоих полей. Выделены следующие фракции, мм: > 1, 1-0.5, 0.5-0.25, 0.25-0.1, 0.1-0.05, < 0.05. Также определены следующие физические характеристики: плотность, влажность и пористость грунтов. Минералогический анализ проведен на базе ОАО «Кольский геологический информационно-лабораторный центр». Вследствие потенциальной опасности загрязнения окружающих водных экосистем фтором, в значительном количестве содержащимся в хвостах, проведено лабораторное моделирование процессов миграции этого элемента из хвостов с водными потоками. Для исследования перехода фтора в подвижные формы проведены опыты по водному выщелачиванию пробы хвостов дистиллированной водой в течение четырех часов. Кроме того, исследовано влияние $\mathrm{pH}$ раствора на интенсивность миграции этого элемента.

\section{Результаты}

Анализом гранулометрического состава установлено, что хвосты I поля характеризуются преобладанием фракций с размером зерен 0.5-0.25 мм (23.5 \%) и 0.25-0.1 мм (33.2\%), тогда как для нового (II) поля характерно гораздо более отчетливое преобладание фракции 0.25-0.1 мм-47.8 \% (Горячев и др., 2019 б). Отмечено характерное различие в относительном содержании частиц размером $>0.5$ мм между двумя исследованными полями. Так, в I поле доля данной фракции достигает $6.4 \%$, при относительном содержании $5.1 \%$ во II поле. Хвосты поверхностного слоя обоих полей по литологической классификации могут быть отнесены к мелко- и среднезернистым пескам. Помимо этого, результаты гранулометрического анализа позволили установить влияние гипергенных процессов на фракционный состав поверхностного слоя хвостохранилища. Для I поля отмечено сравнительно равное распределение исследованных фракций менее 0.5 мм, тогда как для эксплуатируемого в настоящее время поля доля фракции 0.25-0.1 достигла 50 \%. Результаты гранулометрического анализа указывают на то, что при высыхании поверхности хвостохранилища в летний период под воздействием ветровой эрозии велика вероятность пыления хвостов.

Среднее значение влажности поверхностного слоя хвостов I поля составило 18.2 \% (табл. 1), однако в некоторых точках влажность превысила 30 \%, что связано с интенсивным выпадением осадков и последующим их накоплением на поверхности. Влажность хвостов нового поля гораздо выше, по исследованному профилю она составила в среднем $22.0 \%$. Это связано, главным образом, с его текущей эксплуатацией, а также особенностями рельефа местности и взаимным расположением полей - первое поле расположено выше.

Плотность хвостов поверхностного слоя в естественном залегании изменяется в пределах от 1.61 до 1.90 г $/ \mathrm{cm}^{3}$, среднее значение составило 1.73 г $/ \mathrm{cm}^{3}$. Истинная плотность варьирует в диапазоне от 2.64 до 2.83 г/ $\mathrm{cm}^{3}$.

Пористость хвостов I поля изменяется в диапазоне от $40.0 \%$ до $51.8 \%$, среднее значение составило $44.9 \%$, что превышает пористость поверхностного слоя текущего хвостохранилища 42.9 \%. По величине коэффициента пористости пробы обоих полей варьируют, главным образом, от плотных грунтов до грунтов средней плотности (ГОСТ 25100-2011). Тем не менее, сравнение значений пористости двух рассматриваемых полей показало сравнительно более высокую плотность грунтов I поля, коэффициент пористости в среднем составил 0.82 , тогда как для II поля он равнялся 0.77 .

В минеральном составе обоих полей преобладает нефелин, на долю которого приходится более $50 \%$ (рис. 2). Массовое содержание полевых шпатов в I поле составляет $15.3 \%$, тогда как во II поле его содержание достигает 18.5 \%, полевые шпаты представлены альбитом и микроклином. В заметных количествах представлен эгирин, в I поле его содержание превышает массовое содержание полевых шпатов.

Среднее содержание минералов РЗЭ - лопарита и эвдиалита составляет 1.70 \% и 0.63 \% для нового поля. В I поле установлено относительно невысокое содержание лопарита в поверхностном слое $-1.37 \%$, содержание эвдиалита также существенно ниже $-0.06 \%$. Невысокое относительное 
содержание лопарита в поверхностном слое I поля, вероятно, связано с миграцией лопарита в нижние горизонты вследствие его высокой плотности, составляющей приблизительно 4.8 г $/ \mathrm{cm}^{3}$.

Таблица 1. Инженерно-геологические показатели отходов обогащения I поля Карнасуртского рудника.

Table 1. Engineering-geological indicators of the Karnasurtsky mine enrichment tailing dumps (I field).

\begin{tabular}{|c|c|c|c|c|c|c|c|c|c|c|}
\hline \multirow{3}{*}{$\begin{array}{c}\text { Статисти- } \\
\text { ческие пока- } \\
\text { затели }\end{array}$} & \multicolumn{4}{|c|}{ Физические параметры } & \multicolumn{6}{|c|}{ Гранулометрический состав, \% } \\
\hline & \multicolumn{2}{|c|}{$\begin{array}{c}\text { Плотность, } \\
\rho_{\text {ист }} \text { и } \rho_{\mathrm{cp}}, \Gamma / \mathrm{cm}^{3}\end{array}$} & \multirow{2}{*}{$\begin{array}{c}\text { Влажноть, } \\
\%\end{array}$} & \multirow{2}{*}{$\begin{array}{c}\text { Пористоть } \\
\%\end{array}$} & \multirow[t]{2}{*}{$>1 \mathrm{MM}$} & \multirow[t]{2}{*}{$1.0-0.5$} & \multirow[t]{2}{*}{$0.5-0.25$} & \multirow[t]{2}{*}{$0.25-0.1$} & \multirow[t]{2}{*}{$0.1-0.05$} & \multirow[t]{2}{*}{$<0.05$} \\
\hline & $\rho_{\text {ист }}$ & $\rho_{\mathrm{cp}}$ & & & & & & & & \\
\hline Сред. & 2.70 & 1.73 & 18.2 & 23.0 & 0.15 & 6.3 & 23.5 & 33.2 & 20.4 & 16.5 \\
\hline $\begin{array}{l}\text { Доверит. } \\
\text { интервал }\end{array}$ & $2.68-2.72$ & $1.72-1.79$ & $15.3-21.1$ & 20.1-25.9 & $0.01-0.3$ & $0.7-1.8$ & $9.5-37.4$ & $20.6-45$ & $10.2-30$ & $0.18-32.9$ \\
\hline Коэф. вар. & 0.36 & 0.02 & 0.36 & 0.29 & 1.23 & 0.89 & 0.60 & 0.38 & 0.50 & 0.99 \\
\hline
\end{tabular}

Фтор относится к числу химических элементов с высоким коэффициентом водной миграции (Перельман, 1975). В связи с этим особую экологическую опасность представляет его потенциальный перенос с водными потоками в окружающую среду.
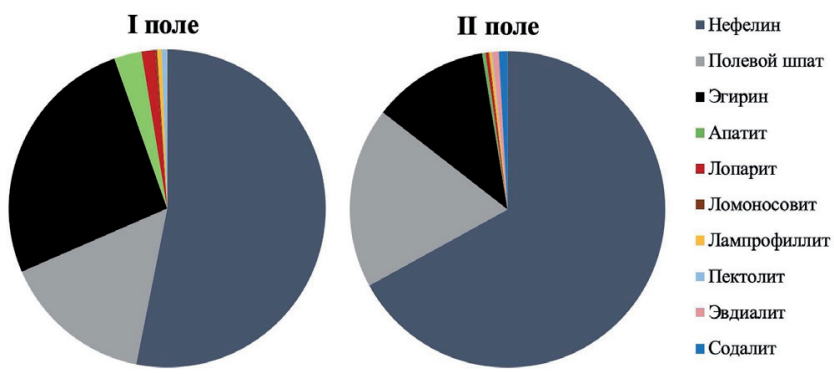

Рис. 2. Минеральный состав хвостов I и II полей.

Fig. 2. Mineral composition of the I and II tailing fields.

В ходе исследования установлено, что миграция фтора в раствор наиболее интенсивно происходит при более высоком значении $\mathrm{pH}$ (табл. 2). Так, с увеличением $\mathrm{pH}$ водной среды в процессе выщелачивания с 2.0 до 4.9 отмечено увеличение содержания фтора с 0.55 мг/л до $2.42 \mathrm{мг/л.}$

При значении $\mathrm{pH}$ равном 5.5 зафиксировано максимальное содержание фтора в растворе - 6.80 мг/л. Снижение $\mathrm{pH}$ до 2.0 привело к существенному снижению миграции фтора, его содержание после 2 часов взаимодействия составило 0.36 мг/л.

Таблица 2. Содержание фтора в водной фазе в зависимости от времени взаимодействия при разном значении $\mathrm{pH}$.

Table 2. The fluorine content in the aqueous phase depending on the reaction time at different $\mathrm{pH}$ values.

\begin{tabular}{|c|c|c|c|}
\hline $\begin{array}{c}\text { Время } \\
\text { взаимодействия }\end{array}$ & $\begin{array}{c}\text { Начальное } \\
\text { значение } \mathrm{pH}\end{array}$ & $\begin{array}{c}\text { Конечное } \\
\text { значение } \mathrm{pH}\end{array}$ & $\begin{array}{c}\text { Содержание } \\
\text { фтора, мг/л }\end{array}$ \\
\hline 14 & \multirow{4}{*}{5.5} & 8.7 & 6.80 \\
\hline 24 & & 8.3 & 5.92 \\
\hline 34 & & 9.3 & 5.52 \\
\hline 4 ч & & 8.5 & 6.36 \\
\hline $1 \mathrm{Y}$ & \multirow{4}{*}{4.0} & 9.3 & 3.99 \\
\hline 24 & & 9.5 & 5.16 \\
\hline 34 & & 9.0 & 5.38 \\
\hline 4 ч & & 8.1 & 6.68 \\
\hline $1 \mathrm{Y}$ & \multirow{4}{*}{3.0} & 7.4 & 5.90 \\
\hline $2 ч$ & & 7.3 & 4.33 \\
\hline 34 & & 7.5 & 6.37 \\
\hline 4 ч & & 7.7 & 6.10 \\
\hline $1 \mathrm{Y}$ & \multirow{4}{*}{2.0} & 4.4 & 0.55 \\
\hline $2 ч$ & & 4.6 & 0.36 \\
\hline 34 & & 4.7 & 1.93 \\
\hline 4 ч & & 4.9 & 2.42 \\
\hline
\end{tabular}




\section{Заключение}

Установлено, что отходы обогащения I поля представляют собой мелкозернистый песок со средней плотностью в естественном залегании равной 1.73 г/см³ , влажностью $18.2 \%$, пористостью $23.0 \%$.

Комплексные исследования инженерно-геологических свойств и минерального состава хвостов обогащения I поля показали, что вследствие гипергенных процессов, оказывающих влияние на поверхностный слой в течение практически семидесяти лет, произошла дифференциация вещества по крупности и плотности, а также сформировалась неоднородность вещественного состава и содержания ценных компонентов. Так, в лежалых хвостах старого поля содержание минералов, заключающих в себе редкие земли, значительно ниже в сравнении с намываемым полем.

Лабораторное моделирование процессов миграции фтора позволило установить увеличение его подвижности при повышении значения рН. Данное свойство способно привести к загрязнению окружающих экосистем вследствие того, что значение $\mathrm{pH}$ поровых растворов колеблется в диапазоне 8.5-9.5 единиц.

Все вышеперечисленные особенности необходимо учитывать при создании технологий переработки исследованного хвостохранилища.

Работа выполнена в рамках темы НИР №№9-18-2514, 0226-2019-0011 и частично поддержана из средств гранта РФФИ (19-05-50065)

\section{Литература}

1. $\quad$ ГОСТ 25100-2011 «Грунты. Классификация».

2. ГОСТ 5180-84 «Грунты. Методы лабораторного определения физических характеристик».

3. Горячев А.А., Лащук В.В., Мартынов Е.В. Методика геоэкологического мониторинга хранилища отходов обогащения редкометальных руд Карнасуртского месторождения (ООО» Ловозерский ГОК», Кольский полуостров) // Труды Ферсмановской научной сессии ГИ КНЦ РАН. 2019 а. №. 16. С. 101-106. DOI: $10.31241 /$ FNS.2019.16.021

4. Горячев А.А., Красавцева Е.А., Лащук В.В., Икконен П.В., Смирнов А.А., Макаров Д.В., Маслобоев В.А. Исследования хвостов обогащения лопаритовых руд // Проблемы и перспективы эффективной переработки минерального сырья в XX в. (Плаксинские чтения-2019). 2019 б. С. 433-434.

5. Лащук В.В., Горячев А.А. Геоэкологическая оценка отходов обогащения редко метальных руд Карнасуртского месторождения (Мурманская область) // Экологические проблемы северных регионов и пути их решения. 2019. С. 325. DOI: 10.31241/FNS.2019.16.021.

6. Перельман А.И. Геохимические барьеры // Природа. 1975. №. 10. С. 55-62.

7. Пожиленко В.И. Геология рудных районов Мурманской области / В.И. Пожиленко, Б.В. Гавриленко, Д.В. Жиров, С.В. Жабин // Апатиты. Изд-во: Кольского НЦ РАН. 2002. 359 с. 